\title{
A randomized, double-blind, placebo-controlled trial of resveratrol for Alzheimer disease OPEN
}

R. Scott Turner, MD, $\mathrm{PhD}$

Ronald G. Thomas, PhD Suzanne Craft, PhD

Christopher H. van Dyck, MD

Jacobo Mintzer, MD

Brigid A. Reynolds, NP

James B. Brewer, MD, $\mathrm{PhD}$

Robert A. Rissman, $\mathrm{PhD}$

Rema Raman, PhD

Paul S. Aisen, MD

For the Alzheimer's

Disease Cooperative Study

Correspondence to

Dr. Turner:

rst36@georgetown.edu
Supplemental data at Neurology.org

\section{ABSTRACT}

Objective: A randomized, placebo-controlled, double-blind, multicenter 52-week phase 2 trial of resveratrol in individuals with mild to moderate Alzheimer disease (AD) examined its safety and tolerability and effects on biomarker (plasma A 40 and A 42 , CSF A $340, A \beta 42$, tau, and phospho-tau 181) and volumetric MRI outcomes (primary outcomes) and clinical outcomes (secondary outcomes).

Methods: Participants ( $n=119)$ were randomized to placebo or resveratrol 500 mg orally once daily (with dose escalation by 500-mg increments every 13 weeks, ending with 1,000 mg twice daily). Brain MRI and CSF collection were performed at baseline and after completion of treatment. Detailed pharmacokinetics were performed on a subset $(n=15)$ at baseline and weeks 13 , 26, 39, and 52.

Results: Resveratrol and its major metabolites were measurable in plasma and CSF. The most common adverse events were nausea, diarrhea, and weight loss. CSF A 40 and plasma A 40 levels declined more in the placebo group than the resveratrol-treated group, resulting in a significant difference at week 52. Brain volume loss was increased by resveratrol treatment compared to placebo.

Conclusions: Resveratrol was safe and well-tolerated. Resveratrol and its major metabolites penetrated the blood-brain barrier to have CNS effects. Further studies are required to interpret the biomarker changes associated with resveratrol treatment.

Classification of evidence: This study provides Class II evidence that for patients with AD resveratrol is safe, well-tolerated, and alters some AD biomarker trajectories. The study is rated Class II because more than 2 primary outcomes were designated. Neurology ${ }^{\circledR}$ 2015;85:1383-1391

\section{GLOSSARY}

3G-RES = 3-O-glucuronidated-resveratrol; 4G-RES $=4$-O-glucuronidated-resveratrol; $\mathbf{A D}=$ Alzheimer disease; ADAS$\operatorname{cog}=$ Alzheimer's Disease Assessment Scale-cognitive; ADCS = Alzheimer's Disease Cooperative Study; ADCS-ADL = Alzheimer's Disease Cooperative Study Activities of Daily Living Scale; AE = adverse event; BMI = body mass index; CDRSOB $=$ Clinical Dementia Rating-sum of boxes; $\mathbf{C}_{\max }=$ maximal plasma concentration; $\mathbf{D M S O}=$ dimethyl sulfoxide; ITT = intention-to-treat; MMRM = mixed-model repeated-measures; MMSE = Mini-Mental State Examination; NPI = Neuropsychiatric Inventory; S-RES = 3-sulfated-resveratrol; SAE = serious adverse event.

Caloric restriction prevents aging-dependent phenotypes ${ }^{1}$ and activates sirtuins (including SIRT1), a highly conserved family of deacetylases that are regulated by NAD+/NADH and thus link energy metabolism to gene expression. ${ }^{2}$ SIRT1 substrates include FOXO and PGC$1 \alpha .^{3}$ A screen of SIRT1 activators identified resveratrol (trans-3,4',5-trihydroxystilbene) as a potent compound. ${ }^{4}$ Similar to caloric restriction, ${ }^{5,6}$ resveratrol decreases aging-dependent cognitive decline and pathology in Alzheimer disease (AD) animal models. ${ }^{7,8}$ Xenohormesis is the ability to transmit resilience to stress from one species to another-for example, via

From the Department of Neurology (R.S.T., B.A.R.), Georgetown University, Washington, DC; the Department of Neurosciences (R.G.T., J.B.B., R.A.R., R.R., P.S.A.), University of California, San Diego, La Jolla; the Department of Internal Medicine (S.C.), Wake Forest University, WinstonSalem, NC; the Departments of Psychiatry, Neurology, and Neurobiology (C.H.v.D.), Yale University, New Haven, CT; and the Clinical Biotechnology Research Institute (J.M.), Roper St. Francis Healthcare, Charleston, SC.

Coinvestigators are listed on the Neurology ${ }^{\circledR}$ Web site at Neurology.org.

Go to Neurology.org for full disclosures. Funding information and disclosures deemed relevant by the authors, if any, are provided at the end of the article. The Article Processing Charge was paid by NIH.

This is an open access article distributed under the terms of the Creative Commons Attribution-NonCommercial-NoDerivatives License 4.0 (CC BY-NC-ND), which permits downloading and sharing the work provided it is properly cited. The work cannot be changed in any way or used commercially. 
consumption of resveratrol-containing foods. ${ }^{9}$ Resveratrol is under investigation to prevent age-related disorders including cancer, diabetes mellitus, and neurodegeneration. ${ }^{4,9-12}$ Due to its low bioavailability but high bioactivity, ${ }^{13,14}$ we increased the dose to the maximal amount considered safe and well-tolerated for this study. ${ }^{15}$

We conducted a randomized, placebocontrolled, double-blind, multicenter 52week phase 2 trial of resveratrol in individuals with mild to moderate AD. The primary objectives were to (1) assess the safety and tolerability of resveratrol; (2) assess effect on plasma and CSF $A \beta 42$ and $A \beta 40$, CSF tau and phospho-tau 181, and volumetric MRI; and (3) examine pharmacokinetics. The secondary objectives were to (1) explore the effects of resveratrol on cognitive, functional, and behavioral outcomes; (2) examine the influence of $A P O E$ genotype; and (3) determine whether resveratrol affects insulin and glucose metabolism. We hypothesized that resveratrol would alter $\mathrm{AD}$ biomarker trajectories.

METHODS Classification of evidence. This study provides Class II evidence that for patients with AD resveratrol is safe, welltolerated, and alters some $\mathrm{AD}$ biomarker trajectories. The study is rated Class II because more than 2 primary outcomes were designated.

Study design. A multicenter, double-blind, placebo-controlled trial was conducted June 2012-March 2014 with participants recruited from 26 US academic clinics affiliated with the Alzheimer's Disease Cooperative Study (ADCS). The enrollment target was 120 (60 per group) randomized to drug or placebo. Actual enrollment was 119. A subgroup of 15 participants enrolled in a randomized 4:1 $(\mathrm{n}=15,12$ treated plus 3 placebo $)$ study for 24-hour pharmacokinetics at selected sites. For these individuals, blood samples were collected at times $0,0.17,0.33$, $0.5,0.67,1,1.5,2,2.5,3,4,6,8,12$, and 24 hours. Measurements included resveratrol, 3-O-glucuronidated-resveratrol (3G-RES), 4-O-glucuronidated-resveratrol (4G-RES), and 3-sulfatedresveratrol (S-RES). These participants completed 24-hour pharmacokinetics at each dosage: after the first dose following baseline, after the first dose with each increment (weeks 13, 26, and 39), and after the final dose (week 52). The afternoon dose of resveratrol was withheld during the 24-hour blood sampling.

Standard protocol approvals, registrations, and patient consents. This study was conducted in accordance with Good Clinical Practice guidelines. Informed consent was obtained from participants and study partners. The study was conducted under local institutional review board supervision, under Food and Drug Administration IND 104205, and registered at ClinicalTrials.gov (NCT01504854)

Study visits. Visits occurred at screening, baseline, and weeks 6 , $13,19,26,32,39,45$, and 52. Visits included concomitant medications and adverse events (AEs) review, physical and neurologic examination, urinalysis, pill count, and venipuncture for laboratory tests, pharmacokinetics, and biomarker analyses. Brain MRIs were obtained at baseline, week 13, and week 52. ECGs and CSF collections were performed at baseline and week 52 . Oral glucose tolerance tests, with peripheral blood mononuclear cell collections at 0 and 120 minutes, were performed at screening and week 52 (except in participants enrolled in the 24-hour pharmacokinetics substudy).

Participants and randomization. Inclusion criteria for enrollment included age $>49$ years, fluent in English or Spanish, diagnosis of probable AD by National Institute of Neurological and Communicative Disorders and Stroke-Alzheimer's Disease and Related Disorders Association criteria, ${ }^{16}$ Mini-Mental State Examination (MMSE) score ${ }^{17} 14-26$ at screening, modified Hachinski Score ${ }^{18}$ $<5$, normal laboratory values, stable medications for 4 months, and stable use of cholinesterase inhibitors or memantine. Exclusion criteria included non-AD dementia, Down syndrome, sensory impairments precluding participation, pregnancy, contraindication to lumbar puncture or MRI, $>4$ microhemorrhages on a recent MRI, treated diabetes mellitus, use of resveratrol-containing supplements, and unsuitable disorder or laboratory finding. Participants were assigned to resveratrol or placebo using a stratified permuted block method with an allocation ratio of 1:1. Assignment to groups was stratified by site. After participants signed informed consent and eligibility was confirmed, study sites received randomization numbers from the Informatics Core. A subgroup $(\mathrm{n}=15)$ was randomized 4:1 (12 treated, 3 placebo) for 24-hour pharmacokinetics. Sample sizes (60 per group) were determined from power analyses utilizing published data on CSF biomarkers in $\mathrm{AD}$ trials, and a predicted $20 \%$ dropout rate.

Study medication. Aptuit Laurus, Inc. (Kansas City, MO, now Catalent, Inc., Somerset, NJ) synthesized and encapsulated resveratrol (trans-3,5,4'-trihydroxystilbene) and provided identical placebo, according to current Good Manufacturing Practices. The dose escalation was in 500-mg increments every 13 weeks as follows: $500 \mathrm{mg}$ QAM, $500 \mathrm{mg}$ BID, 1,000 mg QAM and $500 \mathrm{mg}$ QPM, and 1,000 mg BID.

Outcomes. Primary outcomes were levels of plasma $A \beta 40$ and $A \beta 42$, CSF $A \beta 40, A \beta 42$, tau, and phospho-tau 181, and volumetric MRI (rate of whole brain volume change, rate of ventricular volume change, rate of hippocampal volume change, and rate of entorhinal cortex volume change). Additional outcomes included safety and tolerability (AEs, physical examinations, neurologic examinations, clinical laboratory results) and pharmacokinetics. Secondary outcomes included scores on the MMSE, ${ }^{17}$ Alzheimer's Disease Assessment Scale-cognitive (ADAS$\operatorname{cog}),{ }^{19}$ ADCS Activities of Daily Living Scale (ADCS-ADL), ${ }^{20}$ Clinical Dementia Rating-sum of boxes (CDR-SOB), ${ }^{21}$ and Neuropsychiatric Inventory (NPI), ${ }^{22}$ APOE genotype, and insulin and glucose metabolism (including oral glucose tolerance tests).

Safety assessments. Participants received physical and neurologic examinations and vital signs at each visit. Site investigators classified AEs by severity and causality. If a participant withdrew, an early termination visit similar to a baseline visit was scheduled. An independent Data and Safety Monitoring Board reviewed data quarterly.

Liquid chromatography-mass spectrometry conditions for resveratrol plasma and CSF pharmacokinetics. Stock solutions of resveratrol, hexestrol (Sigma Aldrich, St. Louis, $\mathrm{MO}$ ), trans-resveratrol-3-O- $\beta$-D-glucuronide, trans-resveratrol$4-\mathrm{O}-\beta-\mathrm{D}$-glucuronide, and trans-resveratrol-3-sulfate sodium 
salt (Toronto Research Chemicals Inc., Canada) were suspended to $2 \mathrm{mg} / \mathrm{mL}$ in dimethyl sulfoxide (DMSO). Working stocks of 0.1 $\mathrm{mg} / \mathrm{mL}$ were made in DMSO. Calibrator standards and quality controls were made in human pooled plasma (Gemini Bioproducts, Sacramento, CA). Plasma samples were mixed with acetonitrile with $0.1 \%$ formic acid and centrifuged for 2 minutes to remove precipitate. Pharmacokinetic analysis was performed using an AB Sciex (Framingham, MA) QTRAP 5500 and Shimadzu UFLC XR rack changer liquid chromatography-mass spectrometry system. Data acquisition and analysis was made using Analyst 1.6 (AB Sciex). Quantification was done in Analyst (AB Sciex) by using linear regression with a $1 / \mathrm{x}^{2}$ weighing factor based on goodness-of-fit criteria and coefficient of determination $\left(r^{2}\right)$. The CSF conditions were the same as plasma except the injection volume was $20 \mu \mathrm{L}$. Calibrator standards were made in $50: 50(\mathrm{v} / \mathrm{v})$ acetonitrile and water with $0.1 \%$ formic acid.

Bioassays. The Biomarker Core assayed $A \beta 40$ and $A \beta 42$ in plasma and CSF and tau and phospho-tau 181 in CSF. ${ }^{23}$ Validated assay platforms from Meso Scale Discovery (Rockville, MD) were used to detect $\mathrm{A} \beta$ isoforms and total tau. Innotest pTau181 was used for phospho-tau 181. Internal standards were used to adjust for plate-to-plate variation and assess freezer storage effects. ${ }^{23}$ The Biomarker Core performed $A P O E$ genotyping using real-time PCR restriction fragment length polymorphism analysis. Genomic DNA from blood was extracted using QIAamp DNA blood maxi kit (Qiagen, Venlo, Netherlands) and $A P O E$ genotyping performed using Applied Biosystems (Foster City, CA) TaqMan SNP Genotyping Assay. The assay was run on a Bio-Rad (Hercules, CA) CFX96.

MRI methods. MRIs at baseline, 3 months, and 12 months were acquired using GE (Cleveland, OH), Philips (Best, the
Netherlands), or Siemens (Munich, Germany) 1.5 and $3.0 \mathrm{~T}$ scanners. Site personnel scanned participants longitudinally on the same scanner using a consistent protocol and quality checks confirmed that parameters held constant. Volumetric MRI analysis was performed on 3D T1-weighted volumes acquired sagittally with imaging parameters modeled on the nonaccelerated T1-weighted sequence from the Alzheimer's Disease Neuroimaging Initiative. NeuroQuant (CorTechs Labs, San Diego, CA) image preprocessing and automated segmentation was used to measure whole-brain, hippocampus, and entorhinal volumes ${ }^{24-26}$ and other methods were as described. ${ }^{27-32}$ Regional deformation was quantified and averaged within all segmented areas; however, to reduce multiple comparisons for primary analysis, only ventricular volume change was assessed using longitudinal registration.

Statistical analyses. Mixed-model repeated-measures (MMRM) analyses were used to assess between-group differences in change scores from baseline to week 52 . The dependent variable in each MMRM analysis was change from baseline. Fixed effects included baseline scores on outcome measures, age at baseline, group assignment, study visit, and treatment-by-visit interaction. Additionally, covariates that were significantly associated with the response measure $(p<0.15)$ and were out of balance at baseline $(p<0.2)$ were included as fixed effects. Study visit was modeled as a categorical variable; an autoregressive (order 1) covariance structure was specified. Variables considered as potential covariates in each model included biomarkers CSF total tau, CSF phospho-tau 181, CSF $A \beta 40$, CSF $A \beta 42$, plasma $A \beta 40$, plasma $\mathrm{A} \beta 42$, brain volume, ventricular volume, hippocampal volume, and entorhinal thickness; insulin and glucose; $A P O E$; clinical measures: baseline ADAS-cog, baseline MMSE, and baseline CDR-SOB.

Figure 1 Flow diagram and disposition of the treatment groups

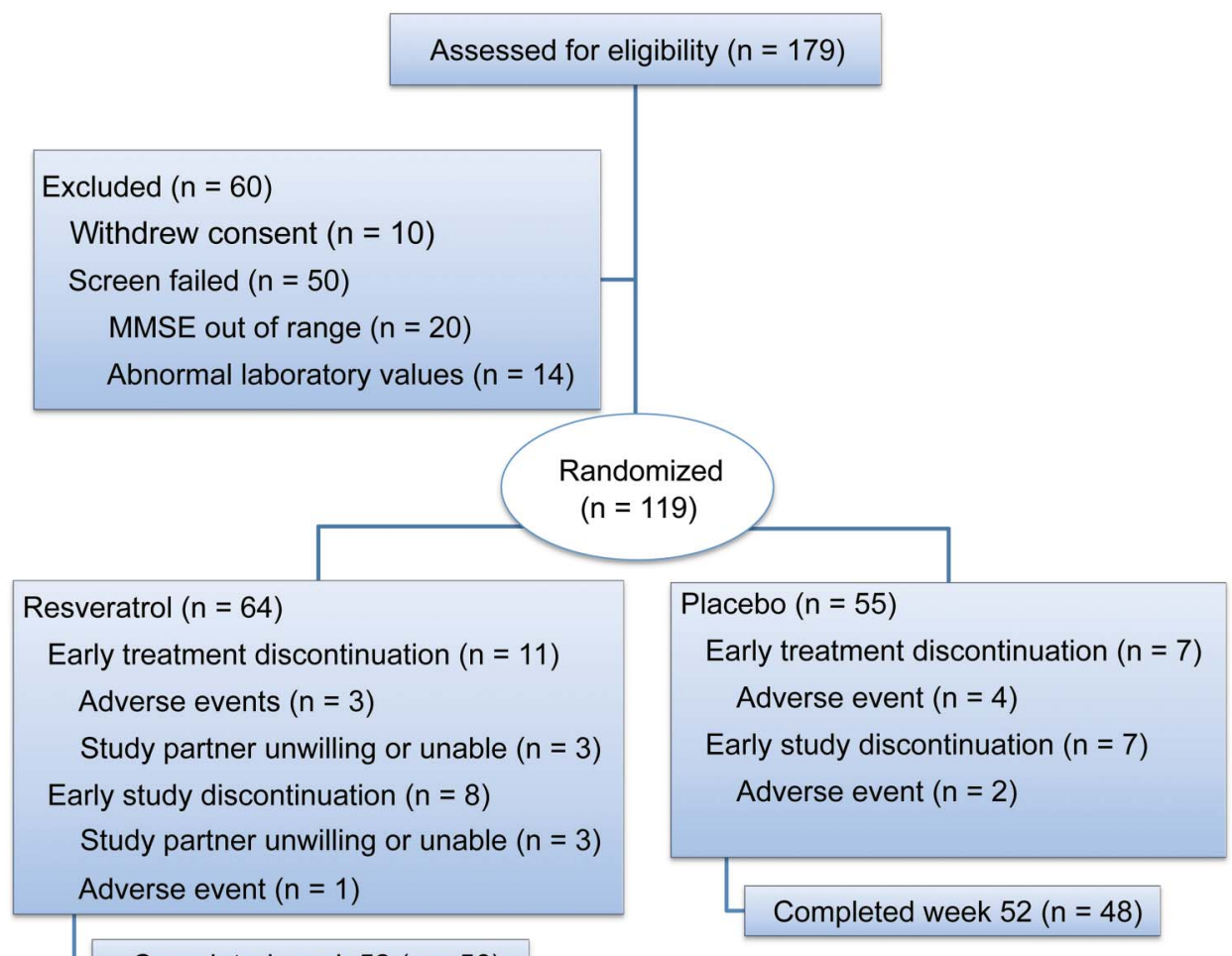

MMSE $=$ Mini-Mental State Examination. 
The key efficacy analysis was based on a modified intentionto-treat (ITT) population, which included all randomly assigned participants with at least one postbaseline observation. Secondary analyses were performed for completers, for APOE4 carriers and noncarriers, and for mild AD (MMSE > 19). The baseline characteristics of the study groups were compared with the use of Fisher exact test for categorical variables and a Wilcoxon signed-rank test for continuous variables. Safety analyses were based on summary listings of AEs, with Fisher exact test used for pairwise comparisons. Safety analyses were based on the full ITT population. $R$ version 3.1 (www.r-project.org) was used for all analyses. A $p$ value $<0.05$ indicated significance. All testing was 2-sided. Blinding of investigators was maintained until outcomes were determined. Results for testing several endpoints were not adjusted.

RESULTS A total of 179 participants were screened, of whom 60 were not randomized (50 screen-failed and 10 withdrew consent). Participants (119) were randomized as shown (figure 1). A total of 104 completed the study (12.6\% dropout), and 77 completed 2 CSF collections (34\% dropout). Eighteen participants discontinued treatment early and 15 discontinued the study. The population was English-speaking, 57\% female, and 91\% Caucasian.

\begin{tabular}{|c|c|c|c|}
\hline \multirow[t]{2}{*}{ Baseline characteristics of th } & \multirow{3}{*}{$\begin{array}{l}\begin{array}{l}\text { Resveratrol } \\
(n=64)^{a}\end{array} \\
40(62.5)\end{array}$} & placebo group & \multirow[b]{2}{*}{$p$ Value } \\
\hline & & $\begin{array}{l}\text { Placebo } \\
(\mathrm{n}=55)^{\mathrm{a}}\end{array}$ & \\
\hline Female, n (\%) & & $28(50.9)$ & $0.27^{b}$ \\
\hline Caucasian, n (\%) & 57 (89.1) & $51(92.7)$ & $0.81^{b}$ \\
\hline Age, y, mean (SD) & $69.8(7.7)$ & $73(8.2)$ & $0.07^{c}$ \\
\hline Education, y, mean (SD) & $15.5(3.0)$ & $14.6(2.9)$ & $0.11^{\mathrm{c}}$ \\
\hline $\begin{array}{l}\text { AD duration (from year of symptom onset), } y \text {, } \\
\text { mean (SD) }\end{array}$ & 3.9 (2.3) & $5.5(2.6)$ & $<0.001$ \\
\hline Weight, kg, mean (SD) & $71.2(15.2)$ & $71.2(13.6)$ & $0.80^{c}$ \\
\hline BMI, mean (SD) & $25.8(4.3)$ & $25.5(4.0)$ & $0.83^{c}$ \\
\hline MMSE, mean (SD) & $20.2(4.4)$ & 20.7 (4.3) & $0.57^{c}$ \\
\hline CDR-SOB, mean (SD) & $5.1(2.4)$ & $5.4(2.3)$ & $0.43^{c}$ \\
\hline ADCS-ADL, mean (SD) & $63.7(10.8)$ & $60.5(10.7)$ & $0.08^{c}$ \\
\hline$N P I$, mean $(S D)^{d}$ & $7.5(7.9)$ & $11.1(11.6)$ & $0.10^{c}$ \\
\hline ADAS-cog, mean (SD) & $25.3(10.1)$ & 23.7 (8.6) & $0.50^{c}$ \\
\hline Brain volume, mL, mean (SD) & 865.9 (84.5) & 850.5 (98.9) & $0.38^{\mathrm{c}}$ \\
\hline Ventricular volume, $\mathrm{mL}$, mean (SD) & $54.5(23.8)$ & 55.6 (19.2) & $0.32^{\mathrm{c}}$ \\
\hline CSF A $\beta 40, n g / m L$, mean (SD) & $6,574(2,346)$ & $6,560(2,190)$ & $0.77^{c}$ \\
\hline Plasma $A \beta 40, \mathrm{ng} / \mathrm{mL}$, mean $(\mathrm{SD})^{f}$ & $163.0(58.2)$ & $165.3(55.4)$ & $0.64^{\mathrm{c}}$ \\
\hline
\end{tabular}

Abbreviations: $A D=$ Alzheimer disease; ADAS-cog $=$ Alzheimer's Disease Assessment Scale-cognitive; ADCS-ADL = Alzheimer's Disease Cooperative Study Activities of Daily Living Scale; $\mathrm{BMI}=$ body mass index; $\mathrm{CDR}-\mathrm{SOB}=$ Clinical Dementia Rating-sum of boxes; MMSE $=$ Mini-Mental State Examination; NPI = Neuropsychiatric Inventory.

${ }^{a}$ Except as indicated.

${ }^{b}$ Fisher exact test.

${ }^{\mathrm{c}}$ Wilcoxon rank-sum test.

${ }^{\mathrm{d}}$ Resveratrol $(\mathrm{n}=63)$.

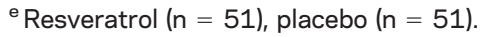

${ }^{f}$ Resveratrol $(n=53)$.
The baseline characteristics revealed that the placebo group had a longer $\mathrm{AD}$ duration (measured from year of symptom onset) (table 1). Results must be interpreted with caution given this caveat. However, a post hoc exploratory analysis found no difference between groups when $\mathrm{AD}$ duration was measured in years from diagnosis, and a post hoc re-analysis adjusting for age and $\mathrm{AD}$ duration in the MMRM model did not alter results, with the exception that difference in ventricular volume became nonsignificant $(p=0.10)$ (appendix e-1 on the Neurology ${ }^{\circledR}$ Web site at Neurology.org).

Safety and tolerability. No differences between the resveratrol and placebo-treated groups were found on vital signs, physical examinations, or neurologic examinations. Routine laboratory tests were normal. A total of 657 AEs (490 mild, 139 moderate, 28 severe) were reported (355 on drug, 302 on placebo) (table 2). A total of 113 out of 119 (95\%) participants reported at least $1 \mathrm{AE}$. The most common AEs were nausea and diarrhea (in $42 \%$ of individuals with drug vs $33 \%$ with placebo, $p=$ 0.35). Few participants reported nausea and diarrhea - the most likely drug-related $\mathrm{AE}$ - that led to treatment discontinuation, a treatment plateau at a lower dosage, or study discontinuation (figure 1). The placebo group gained $0.54 \pm 3.2 \mathrm{~kg}$ body weight, while the treated group lost $0.92 \pm 4.9 \mathrm{~kg}$ (mean \pm $\mathrm{SD}, p=0.038$ ) resulting in a difference in body mass index (BMI). The treated group's BMI was $25.4 \pm$ 4.0 vs the placebo group's $26.1 \pm 4.1$ at week 52 (mean $\pm \mathrm{SD}, p=0.047$ ).

Thirty-six serious AEs (SAEs) were reported (19 on drug, 17 on placebo) including 27 hospitalizations (14 on drug, 13 on placebo) and 3 deaths (1 on drug, 2 on placebo) — none study drug-related. There were no differences in participants who experienced at least one SAE ( $20.3 \%$ on drug, $18.2 \%$ on placebo), at least one hospitalization (18.8\% drug, $16.4 \%$ placebo), or died (1.6\% drug, $3.6 \%$ placebo). Seven new neoplasms were reported ( 1 on drug, 6 on placebo, $p<0.048$ ) (table 2). Retrospective review of the brain MRIs of a placebo-enrolled participant with malignant glioma, which resulted in death, revealed that the tumor was present at screening. Two participant deaths were due to lung melanoma (placebo group) and drowning (drug group).

Pharmacokinetics. Metabolites of resveratrol include 3G-RES, 4G-RES, and S-RES. A 24-hour pharmacokinetic substudy determined the maximal plasma concentrations $\left(\mathrm{C}_{\max }\right)$ of resveratrol and its metabolites at baseline and weeks 13, 26, 39, and 52. The $C_{\max }, t_{\max }$, and half-life of resveratrol and its metabolites at week 52 are shown in table e-1. Resveratrol pharmacokinetics in plasma from the 
Table 2 Participants with adverse events by system

\begin{tabular}{|c|c|c|c|}
\hline System & $\begin{array}{l}\text { Resveratrol } \\
(n=64), n(\%)\end{array}$ & $\begin{array}{l}\text { Placebo }(n=55) \\
n(\%)\end{array}$ & p Value ${ }^{a}$ \\
\hline Infections and infestations & 27 (42.2) & $23(41.8)$ & $>0.999$ \\
\hline Nervous system disorders ${ }^{b}$ & 25 (39.1) & 21 (38.2) & $>0.999$ \\
\hline Gastrointestinal disorders $^{c}$ & 27 (42.2) & $18(32.7)$ & 0.345 \\
\hline Psychiatric disorders & 23 (35.9) & $18(32.7)$ & 0.847 \\
\hline $\begin{array}{l}\text { Injury, poisoning, or procedural } \\
\text { complications }^{d}\end{array}$ & $22(34.4)$ & $16(29.1)$ & 0.561 \\
\hline Investigations ${ }^{e}$ & 25 (39.1) & $12(21.8)$ & 0.049 \\
\hline $\begin{array}{l}\text { Musculoskeletal and connective tissue } \\
\text { disorders }^{f}\end{array}$ & $15(23.4)$ & $20(36.4)$ & 0.158 \\
\hline $\begin{array}{l}\text { General disorders and administrative site } \\
\text { conditions }\end{array}$ & $12(18.8)$ & $12(21.8)$ & 0.819 \\
\hline $\begin{array}{l}\text { Respiratory, thoracic, and mediastinal } \\
\text { disorders }\end{array}$ & 13 (20.3) & $10(18.2)$ & 0.819 \\
\hline Skin and subcutaneous tissue disorders ${ }^{9}$ & 7 (10.9) & $12(21.8)$ & 0.134 \\
\hline Renal and urinary disorders & 7 (10.9) & $9(16.4)$ & 0.429 \\
\hline Vascular disorders & $8(12.5)$ & $5(9.1)$ & 0.769 \\
\hline Cardiac disorders & $5(7.8)$ & 6 (10.9) & 0.753 \\
\hline Eye disorders & $5(7.8)$ & 6 (10.9) & 0.753 \\
\hline Metabolism and nutrition disorders & $5(7.8)$ & $6(10.9)$ & 0.753 \\
\hline $\begin{array}{l}\text { Neoplasms benign, malignant, and } \\
\text { unspecified }\end{array}$ & $1(1.6)$ & 6 (10.9) & 0.048 \\
\hline
\end{tabular}

${ }^{a}$ Fisher exact test.

The most frequent events by system and by participant were ${ }^{\mathrm{b}}$ headache (11 on drug, 6 on placebo); ${ }^{\mathrm{c}}$ diarrhea (26 on drug, 7 on placebo), nausea (14 on drug, 5 on placebo); ${ }^{\mathrm{d}}$ fall (22 on drug, 14 on placebo); ${ }^{\mathrm{e}}$ weight decrease ( 11 on drug, 0 on placebo); ${ }^{\mathrm{f}}$ back pain ( 7 on drug, 15 on placebo), arthralgia ( 1 on drug, 7 on placebo); ${ }^{9}$ rash ( 1 on drug, 7 on placebo); ${ }^{\mathrm{h}}$ one bladder cancer on drug and 7 cancers in 6 participants on placebo-3 malignant melanoma, 2 squamous cell carcinoma, 1 basal cell carcinoma, and 1 malignant glioma.

entire study population are shown in figure e-1 (A-D) and week 52 CSF levels are shown in figure e-2 (A-D). These pharmacokinetic results confirmed compliance in both groups.

Outcomes. At week 52, the treated group's CSF A $\beta 40$ declined from $6,574 \pm 2,346$ to $6,513 \pm 2,279$ $\mathrm{ng} / \mathrm{mL}$ and from $6,560 \pm 2,190$ to $5,622 \pm 1,736$ $\mathrm{ng} / \mathrm{mL}$ with placebo, resulting in a difference at week 52 (mean $\pm \mathrm{SD}, p=0.002$ ) (figure $2 \mathrm{~A})$. This difference was also found in secondary analyses of study completers $(p=0.002)$, in the mild dementia subgroup ( $p=0.01)$, and in APOE4 carriers $(p=0.05)$ and noncarriers $(p=0.01)$ (table e-2). During the study, the treated group's plasma $\mathrm{A} \beta 40$ (figure $2 \mathrm{~B}$ ) declined from $163 \pm 58$ to $153 \pm 54 \mathrm{ng} / \mathrm{mL}$ and from $165 \pm 55$ to $132 \pm 54 \mathrm{ng} / \mathrm{mL}$ with placebo (mean $\pm \mathrm{SD}, p=0.024$ ). Secondary analyses by APOE4 genotype revealed an effect of treatment on plasma $\mathrm{A} \beta 40$ in APOE4 carriers $(p=0.04)$ but not noncarriers (table e-2). There were no effects on CSF $A \beta 42$ or plasma $A \beta 42$ (figure $2, C$ and $D$ ), although trends were similar to $A \beta 40$. There was no difference in CSF tau and a trend toward an increase in CSF phospho-tau 181 with treatment $(p=0.08)$, and in a secondary analysis of mild dementia $(p=0.047)$ (data not shown).

Volumetric MRIs revealed that brain volume (excluding CSF, brainstem, and cerebellum) declined more in the treatment group $(p=0.025)$ with an increase in ventricular volume ( $p=0.05)$ at week 52 (figure 3, A and B). In the treatment group, brain volume decreased from $866 \pm 84$ to $839 \pm 85 \mathrm{~mL}$ and ventricular volume increased from $55 \pm 24$ to $81 \pm 24 \mathrm{~mL}$ (mean $\pm \mathrm{SD}$ ). With placebo, brain volume decreased from $850 \pm 99$ to $840 \pm 93 \mathrm{~mL}$ and ventricular volume increased from $56 \pm 19$ to $76 \pm 25 \mathrm{~mL}$ (mean $\pm \mathrm{SD}$ ). Secondary analyses revealed that brain volume declined with treatment in APOE4 carriers $(p=0.02)$ but not noncarriers (table e-2). Similar results were found with ventricular volume, which increased with treatment in APOE4 carriers $(p=0.05)$ but not noncarriers.

This phase 2 trial (underpowered to detect differences in clinical outcomes) found no significant effects on CDR-SOB, ADAS-cog, MMSE, or NPI. The drugtreated group's ADCS-ADL declined from $63.7 \pm$ 10.8 to $57.4 \pm 12.3$ and from $60.5 \pm 10.7$ to $51.3 \pm 14.5$ in the placebo group (mean $\pm \mathrm{SD}$, $p=0.03$ ), indicating less decline with treatment. No drug effects were found with plasma glucose or insulin metabolism (data not shown). We also analyzed (post hoc) the subset of individuals with CSF $A \beta 42$ $<600 \mathrm{ng} / \mathrm{mL}$ at baseline as a proxy of $\mathrm{AD}$ amyloid pathology. At week 52, differences between treatment groups persisted for CSF $A \beta 40(p=0.001$, total $\mathrm{n}=$ 70) and plasma $A \beta 40(p=0.02, n=83)$. In this analysis, we also found a treatment effect on CSF $\mathrm{A} \beta 42(p=0.02, \mathrm{n}=70)$ but lost significance in brain volume loss $(p=0.06, \mathrm{n}=83)$ and ADCS$\operatorname{ADL}(p=0.055, \mathrm{n}=88)$.

DISCUSSION High-dose oral resveratrol is safe and well-tolerated. The most common AEs were nausea and diarrhea, but results were similar to placebo. Weight and fat loss with resveratrol are reported in some preclinical studies, ${ }^{4}$ but human studies are scarce and of shorter duration. A decrease in body fat and a trend toward weight loss were reported in a 26week trial with $200 \mathrm{mg} /$ day resveratrol in healthy older participants. ${ }^{33}$ Weight and fat loss may be related to enhanced mitochondrial biogenesis mediated by SIRT1 activation of PCG- $1 \alpha{ }^{4,10,11}$

$\mathrm{A} \beta$ levels declined as dementia advanced. The altered CSF A $\beta 40$ trajectory suggests that the drug penetrated the blood-brain barrier to have central effects. At week 52, the mean CSF levels of resveratrol, 3G-RES, 4G-RES, and S-RES were 3.3\%, $0.4 \%, 0.4 \%$, and $0.3 \%$, respectively, of plasma levels at the same study visit. At the highest dosage, low $\mu \mathrm{M}$ 

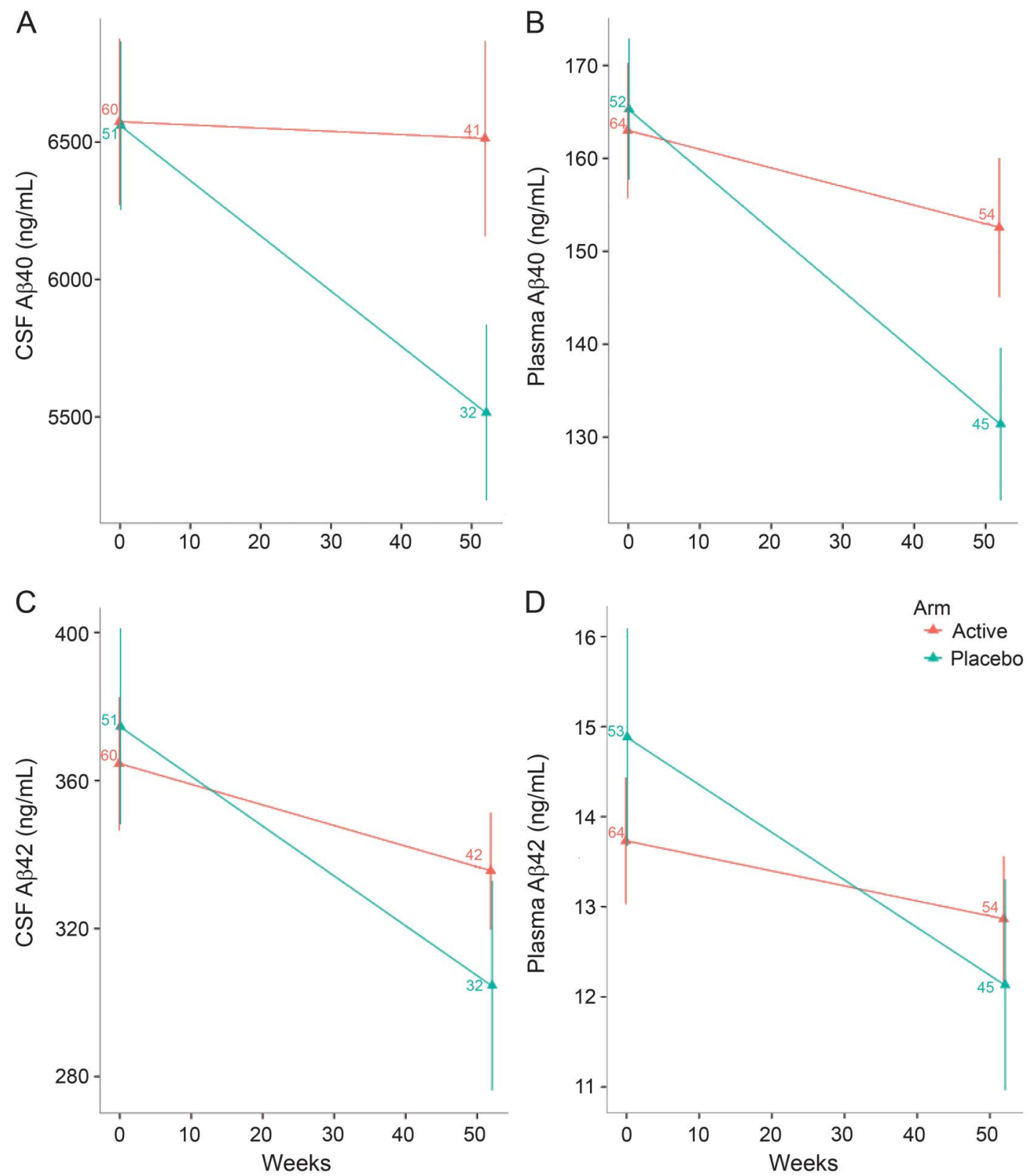

Resveratrol altered levels of CSF A $440(A)$ and plasma $A \beta 40(B)(\mathrm{ng} / \mathrm{mL}$, mean $\pm S E)$. Similar but nonsignificant trends were found for CSF A 342 (C) and plasma A 42 (D) (ng/mL, mean \pm SE). Note difference in scales. Sample sizes are indicated.

levels of resveratrol and its metabolites were measured in plasma, with corresponding low $\mathrm{nM}$ levels found in CSF. Resveratrol has many targets, with some engaged at $\mathrm{uM}$ concentrations. ${ }^{4}$ These findings suggest that a central molecular target may be engaged at nM concentrations. In addition to anti-inflammatory, antioxidant, and anti-A $\beta$ aggregation, putative targets include sirtuin activation with enhanced $\alpha$-cleavage of amyloid precursor protein ${ }^{34}$ and promotion of autophagy. ${ }^{35}$ Further studies of banked CSF, plasma, pellets, DNA, and blood mononuclear cells from participants will examine mechanisms.

Resveratrol treatment increased brain volume loss. This finding persisted when participants with weight loss (table 2) were excluded (data not shown). The etiology and interpretation of brain volume loss observed here and in other studies are unclear, but they are not associated with cognitive or functional decline. In the first human active $A \beta$ immunization trial, antibody responders had greater brain volume loss, and greater volumetric changes were associated with higher antibody titers. ${ }^{36}$ In the phase 2 bapineuzumab trial, treatment resulted in greater ventricular enlargement, but only in APOE4 carriers. ${ }^{37}$ In the phase 3 bapineuzumab APOE4 carrier trial and the high-dose noncarrier study, treatment resulted in a trend toward greater brain atrophy. ${ }^{38}$ Since this phase 2 study lacks consistent changes in clinical outcomes, 

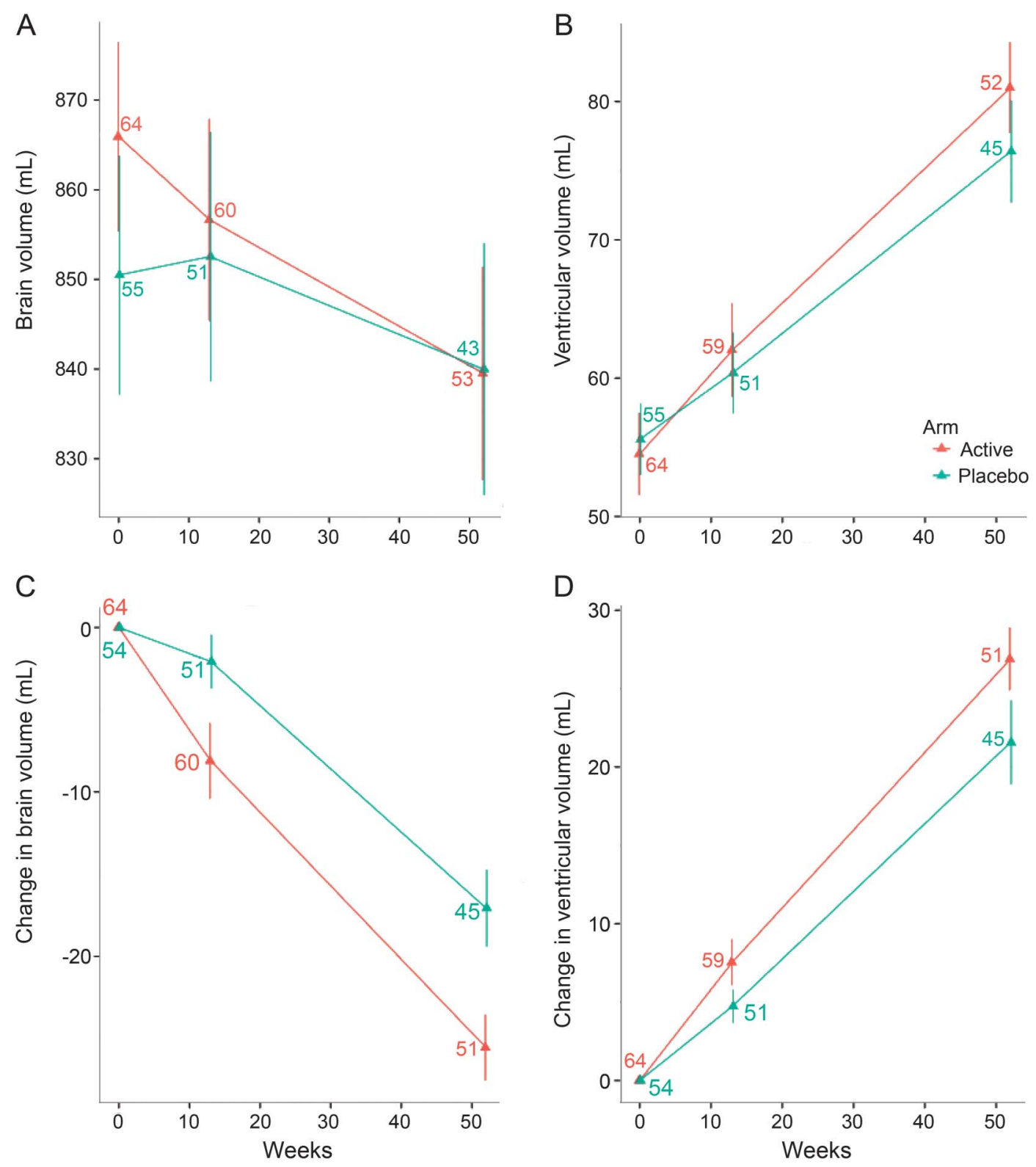

Resveratrol increased brain volume loss $(A, C)(m L$, mean $\pm S E)$ with a corresponding increase in ventricular volume $(B, D)$ $(\mathrm{mL}$, mean $\pm \mathrm{SE})$. Sample sizes are indicated.

interpretation of the effects on trajectories for plasma and CSF $A \beta 40$, and brain and ventricular volume, remain uncertain.

This phase 2 study has limitations. It was designed to determine the safety and tolerability of resveratrol and to examine pharmacokinetics. Although some biomarker trajectories were altered, we found no effects of drug treatment on plasma $A \beta 42$, CSF A 342 , CSF tau, CSF phospho-tau 181, hippocampal volume, entorhinal cortex thickness, MMSE, CDR, ADAS-cog, NPI, or glucose or insulin metabolism. The altered biomarker trajectories must be interpreted with caution. Although they suggest CNS effects, they do not indicate benefit. A larger study is required to determine whether resveratrol may be beneficial. More potent and bioavailable SIRT1 activators are also in development. ${ }^{39,40}$

\section{AUTHOR CONTRIBUTIONS}

R.S. Turner conceived and designed the study with P.S. Aisen and S. Craft. R.G. Thomas and R. Raman performed data analyses. C.H. van Dyck., J. Mintzer, and B.A. Reynolds were the leading site PIs—at Yale University, the Medical University of South Carolina, and Georgetown University, respectively-in recruitment of participants and study partners. J.B. Brewer performed volumetric MRI analyses and R.A. Rissman performed biomarker and pharmacokinetic assays. R.S. Turner performed data analysis, prepared the figures, and drafted the manuscript, which was edited and approved by all authors, members of the Data Safety and Monitoring Board, and the Publications Committee of the ADCS.

\section{ACKNOWLEDGMENT}

The authors thank the participants and their study partners; the study teams at each site (including K.E. Behan, C. Ward, D. Santos, and 
C. Sawda at Georgetown University); the Data Safety and Monitoring Board; the coordinating center staff of the Alzheimer's Disease Cooperative Study (ADCS); the NIA; and L. Monte, S. Campbell, and S. Moghadam of the ADCS Biomarker Core.

\section{STUDY FUNDING}

Supported by the NIH (NIA U01 AG010483 to P.S.A.). ClinicalTrials gov identifier NCT01504854. FDA IND 104205 (Resveratrol for Alzheimer's disease) to R.S.T.

\section{DISCLOSURE}

R. Turner has received research support from Ceregene, Eli Lilly, Merck, Biogen Idec, Toyama, Elan/Transition Therapeutics, and Pfizer, as well as the NIH (NIA U01 AG10483) and the DOD. R. Thomas and S. Craft report no disclosures relevant to the manuscript. C. van Dyck has served as a consultant to Elan, Janssen, Pfizer, Bristol-Myers Squibb, Roche, and AbbVie, and received research support from Elan, BristolMyers Squibb, Eli Lilly, Wyeth, Pfizer, Janssen, Medivation, Baxter, Eisai, Biogen Idec, Merck, Roche, Genentech, TauRx, Forum, Toyama, and the NIH (NCATS UH3 TR000967-02 [PI], NINDS R01 NS087568 [Co-I], and NIA RO1 AG046543 [Co-I]). J. Mintzer has received research support from Takeda, Pfizer, Merck, Genentech, Eli Lilly, Transition Therapeutics, Roche, and Avanir, Grifols, as well as the NIH (NIA U01 AG10483). J. Mintzer is a majority owner of BioPharma Connex, a company that has active contracts with Avanir, Roche, and Eli Lilly for either facilitating recruitment or neuroimaging operations facilitation in Latin America. J. Mintzer is the VP of Medical Affairs at NeuroQuest, a company developing a biomarker for Alzheimer disease. B. Reynolds reports no disclosures relevant to the manuscript. J. Brewer is an investigator for and receives research funds from Navidea and General Electric. J Brewer has served on advisory boards for Elan, BristolMyers Squibb, Avanir, Novartis, Genentech, and Eli Lilly and holds stock options in CorTechs Labs, Inc. and Human Longevity, Inc. R. Rissman and R. Raman report no disclosures relevant to the manuscript. P. Aisen serves on a scientific advisory board for NeuroPhage, has served as a consultant to Elan, Wyeth, Eisai, Bristol-Myers Squibb, Eli Lilly, NeuroPhage, Merck, Roche, Amgen, Genentech, Abbott, Pfizer, Novartis, Bayer, Astellas, Otsuka, Daiichi, AstraZeneca, Janssen, Medivation, Ichor, Toyama, Lundbeck, Biogen Idec, iPerian, Probiodrug, Somaxon, Biotie, Cardeus, Anavex, Kyowa Hakko Kirin Pharma, Medtronic, AbbVie, and Cohbar, and receives research support from Eli Lilly and the NIH (NIA U01 AG10483 [PI], NIA U01 AG024904 [Coordinating Center Director], NIA R01 AG030048 [PI], and R01 AG16381 [Co-I]). Go to Neurology.org for full disclosures.

Received January 6, 2015. Accepted in final form June 19, 2015.

\section{REFERENCES}

1. Cohen HY, Miller C, Bitterman KJ, et al. Calorie restriction promotes mammalian cell survival by inducing the SIRT1 deacetylase. Science 2004;305:390-392.

2. Mattson MP. Energy intake and exercise as determinants of brain health and vulnerability to injury and disease. Cell Metab 2012;16:706-722.

3. Howitz KT, Bitterman KJ, Cohen HY, et al. Small molecule activators of sirtuins extend Saccharomyces cerevisiae lifespan. Nature 2003;425:191-196.

4. Kulkarni SS, Canto C. The molecular targets of resveratrol. Biochim Biophys Acta 2015;1852:1114-1123.

5. Patel NV, Gordon MN, Connor KE, et al. Caloric restriction attenuates $\mathrm{A} \beta$-deposition in Alzheimer transgenic models. Neurobiol Aging 2005;26:995-1000.

6. Wang J, Ho L, Qin W, et al. Caloric restriction attenuates beta-amyloid neuropathology in a mouse model of Alzheimer's disease. FASEB J 2005;19:659-661.

7. Marambaud P, Zhao H, Davies P. Resveratrol promotes clearance of Alzheimer's disease amyloid- $\beta$ peptides. J Biol Chem 2005;280:37377-37382.
8. Karuppagounder SS, Pinto JT, Xu H, et al. Dietary supplementation with resveratrol reduces plaque pathology in a transgenic mouse model of Alzheimer's disease. Neurochem Int 2009;28:1393-1405.

9. Hooper PL, Hooper PL, Tytell M, Vigh L. Xenohormesis: health benefits from an eon of plant stress response evolution. Cell Stress Chaperones 2010;15:761-770.

10. Bastianetto S, Menard C, Quirion R. Neuroprotective action of resveratrol. Biochim Biophys Acta 2015;1852: 1195-1201.

11. Pasinetti GM, Wang J, Ho L, et al. Roles of resveratrol and other grape-derived polyphenols in Alzheimer's disease prevention and treatment. Biochim Biophys Acta (in press 2015).

12. Aguirre A, Fernandez-Quintela A, Aria N, Portillo MP. Resveratrol: anti-obesity mechanisms of action. Molecules 2014;19:18632-18655.

13. Walle T, Hsieh F, DeLegge MH, et al. High absorption but very low bioavailability of oral resveratrol in humans. Drug Metab Dispos 2004;32:1377-1382.

14. Cottart CH, Nivet-Antoine V, Laguillier-Morizot C, Beaudeux JL. Resveratrol bioavailability and toxicity in humans. Mol Nutr Food Res 2010;54:7-16.

15. Tome-Carneiro J, Larrosa M, Gonzalez-Sarrias A, et al. Resveratrol and clinical trials: the crossroad from in vitro studies to human evidence. Curr Pharmacol Des 2013;19: 6064-6093.

16. McKhann G, Drachman D, Folstein M, et al. Clinical diagnosis of Alzheimer's disease: report of the NINDCSADRDA Work Group under the auspices of the Department of Health and Human Services Task Force on Alzheimer's disease. Neurology 1984;34:939-944.

17. Folstein MF, Folstein SE, McHugh PH. Mini-mental state: a practical method for grading the cognitive state of patients for the clinician. J Psychiatr Res 1975;12: 189-198.

18. Rosen WG, Terry RD, Fuld PA, et al. Pathological verification of ischemic score in differentiation of dementia. Ann Neurol 1980;7:586-588.

19. Rosen WG, Mohs RC, Davis KL. A new rating scale for Alzheimer's disease. Am J Psychiatr 1984;141:1356-1364.

20. Galasko D, Kershaw PR, Schneider L, et al. Galatamine maintains ability to perform activities of daily living in patients with Alzheimer's disease. J Am Geriatr Soc 2004;52:1070-1076.

21. Morris JC. The Clinical Dementia Rating (CDR): current version and scoring rules. Neurology 1993;43:2412-2414.

22. Cummings LM, Mega M, Gray K, et al. The Neuropsychiatric Inventory: comprehensive assessment of psychopathology in dementia. Neurology 1994;44:2304-2314.

23. Donohue MC, Moghadam SH, Roe AD, et al. Longitudinal plasma amyloid beta in Alzheimer's disease clinical trials. Alzheimer's Dement Epub 2014 Oct 6.

24. Brewer JB, Magda S, Airriess C, Smith ME. Fully-automated quantification of regional brain volumes for improved detection of focal atrophy in Alzheimer disease. AJNR Am J Neuroradiol 2009;30:578-580.

25. Kovacevic S, Rafii MS, Brewer JB. High-throughput, fully automated volumetry for prediction of MMSE and CDR decline in mild cognitive impairment. Alzheimer Dis Assoc Disord 2009;23:139-145.

26. Heister D, Brewer JB, Magda S, et al. Predicting MCI outcome with clinically available MRI and CSF biomarkers. Neurology 2011;77:1619-1628. 
27. Jovicich J, Czanner S, Greve D, et al. Reliability in multisite structural MRI studies: effects of gradient non-linearity correction on phantom and human data. Neuroimage 2006; 30:436-443.

28. Sled JG, Zijdenbos AP, Evans AC. A nonparametric method for automatic correction of intensity nonuniformity in MRI data. IEEE Trans Med Imaging 1998;17:87-97.

29. Arnold JB, Liow JS, Schaper KA, et al. Qualitative and quantitative evaluation of six algorithms for correcting intensity nonuniformity effects. Neuroimage 2001;13: 931-943.

30. Fischl B, Salat DH, Busa E, et al. Whole brain segmentation: automated labeling of neuroanatomical structures in the human brain. Neuron 2002;33:341-355.

31. Holland D, Dale AM; the Alzheimer's Disease Neuroimaging Initiative. Nonlinear registration of longitudinal images and measurement of change in regions of interest. Med Image Anal 2011;15:489-497.

32. Holland D, McEvoy LK, Dale AM. Unbiased comparison of sample size estimates from longitudinal structural measures in ADNI. Hum Brain Mapp 2012;33:2586-2602.

33. Witte AV, Kerti L, Margulies DS, Floel A. Effects of resveratrol on memory performance, hippocampal functional con- nectivity, and glucose metabolism in healthy older adults. J Neurosci 2014;34:7862-7870.

34. Donmez G, Wang D, Cohen DE, Gaurente L. SIRT1 suppresses beta-amyloid production by activating the alpha secretase gene ADAM10. Cell 2010;142:320-332.

35. Pallauf K, Rimbach G. Autophagy, polyphenols and healthy ageing. Ageing Res Rev 2013;12:237-252.

36. Fox NC, Black RS, Gilman $S$, et al. Effects of $A \beta$ immunization (AN1792) on MRI measures of cerebral volume in Alzheimer disease. Neurology 2005;64:1563-1572.

37. Salloway S, Sperling R, Gilman S, et al. A phase 2 multiple ascending dose trial of bapineuzumab in mild to moderate Alzheimer disease. Neurology 2009;73:2061-2070.

38. Salloway S, Sperling R, Fox NC, et al. Two phase 3 trials of bapineuzumab in mild-to-moderate Alzheimer's disease. N Engl J Med 2014;370:322-333.

39. Mercken EM, Mitchell SJ, Martin-Montalvo A, et al. SRT2014 extends survival of male mice on a standard diet and preserves bone and muscle mass. Aging Cell 2014;13: 787-796.

40. Hubbard BP, Sinclair DA. Small molecule SIRT1 activators for the treatment of aging and age-related disease. Trends Pharmacol Sci 2014;35:146-154.

\section{Get Connected. Stay Connected.}

Connect with the American Academy of Neurology's popular social media channels to stay up-todate on the latest news and breakthroughs in neurology, and network with peers and neurology thought leaders. Visit $A A N . c o m / C o n n e c t$.

\section{Visit the Neurology ${ }^{\circledR}$ Web Site at Neurology.org}

- Enhanced navigation format

- Increased search capability

- Highlighted articles

- Detailed podcast descriptions

- RSS Feeds of current issue and podcasts

- Personal folders for articles and searches

- Mobile device download link

- AAN Web page links

- Links to Neurology Now ${ }^{\circledR}$, Neurology Today ${ }^{\circledR}$, and Continuum ${ }^{\circledR}$

- Resident \& Fellow subsite

(1) Find Neurolog ${ }^{\circledR}$ on Facebook: http://tinyurl.com/neurologyfan

Follow Neurology ${ }^{\circledR}$ on Twitter: https://twitter.com/GreenJournal 


\section{Neurology}

\section{A randomized, double-blind, placebo-controlled trial of resveratrol for Alzheimer disease}

R. Scott Turner, Ronald G. Thomas, Suzanne Craft, et al.

Neurology 2015;85;1383-1391 Published Online before print September 11, 2015

DOI 10.1212/WNL.0000000000002035

This information is current as of September 11, 2015

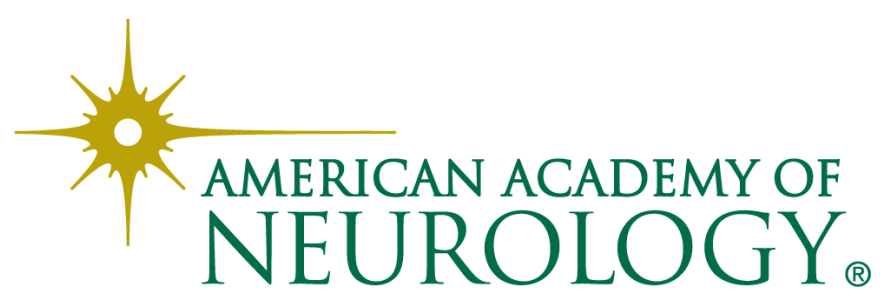




\section{Updated Information \& Services}

\section{Supplementary Material}

\section{References}

Citations

Subspecialty Collections

\section{Permissions \& Licensing}

Reprints including high resolution figures, can be found at: http://n.neurology.org/content/85/16/1383.full

Supplementary material can be found at: http://n.neurology.org/content/suppl/2015/09/11/WNL.0000000000002 035.DC1

http://n.neurology.org/content/suppl/2015/09/11/WNL.0000000000002 035.DC2

This article cites 38 articles, 10 of which you can access for free at: http://n.neurology.org/content/85/16/1383.full\#ref-list-1

This article has been cited by 1 HighWire-hosted articles: http://n.neurology.org/content/85/16/1383.full\#\#otherarticles

This article, along with others on similar topics, appears in the following collection(s):

\section{Alzheimer's disease}

http://n.neurology.org/cgi/collection/alzheimers_disease

\section{Class II}

http://n.neurology.org/cgi/collection/class_ii

Clinical trials Randomized controlled (C) CONSORT agreement)

http://n.neurology.org/cgi/collection/clinical_trials_randomized_control led_consort_agreement

Volumetric MRI

http://n.neurology.org/cgi/collection/volumetric_mri

Information about reproducing this article in parts (figures,tables) or in its entirety can be found online at:

http://www.neurology.org/about/about_the_journal\#permissions

Information about ordering reprints can be found online:

http://n.neurology.org/subscribers/advertise

Neurology ${ }^{\circledR}$ is the official journal of the American Academy of Neurology. Published continuously since 1951, it is now a weekly with 48 issues per year. Copyright @ 2015 American Academy of Neurology. All rights reserved. Print ISSN: 0028-3878. Online ISSN: 1526-632X.

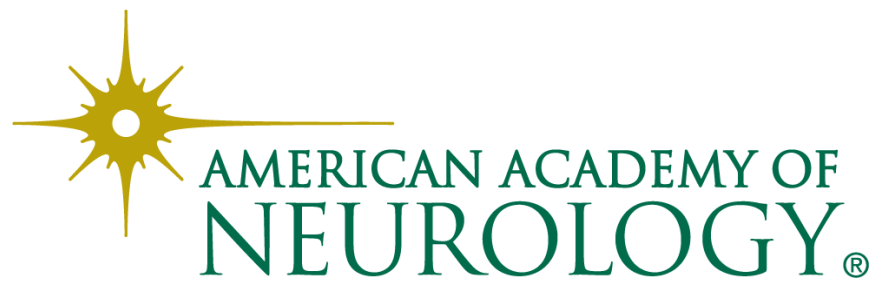

